\title{
Adaptation of Space Activities The Disabled In Urban open Space(a Case Study of Merdeka Square Malang)
}

\author{
Rini Trisulowati \\ Doctoral Program Study of Environmental Studies and DevelopmentBrawijaya University Malang, Indonesia
}

\begin{abstract}
This study aimed to analyze the adaptation of disabled people in the activity room of urban open space and identify alternative solutions that can be applied in the service of a fair and open spaces pro disabilities. This research is a descriptive study using a qualitative approach, where researchers aimed to describe and analyze the performance of adaptation to space activities for the disabled in the city open space as forming environment in the square Merdeka Malang. The collection of primary data collected through field surveys based on visual square Merdeka Malang, environmental and other architectural elements into details such as photos or records the current conditions. The results showed that the provision of services on an open space to meet the needs of disabled people has not been optimal. Barriers that prevent disabled people in open spaces include vehicle parking area, toilet or washroom and signs or do not meet the standards for disabled people.
\end{abstract}

Keywords: adaptation of space activities, disability, urban open space

\section{INTRODUCTION}

Human adaptation to the environment is the human ability to adjust to every condition and situation of ever-changing environment. The process of forming patterns of activity that is always tied to space items, namely the surface of the earth, both on land and at sea. The behavior is a form of adaptation or human reaction to environmental conditions for survival. How to adapt to different geographical conditions. The influence of geographical situation can be observed in the properties of the population. In the face of life's challenges and to survive, humans use 4 things from themselves, that a mind, feeling / emotional, physical, communication. The city is home to shape human behavior. Behavior formed because of the stimulus received and then in response by humans within the meaning derived from knowledge and experience. The term people with disabilities are not only focused on Reviews those with disabilities but the term disabilities have the idea of a more flexible and comprehensive, that people who have barriers Temporarily or permanently in carrying out their daily activities, Including pregnant women, children, the elderly, wheelchair users, crutches, blind, deaf, quadriplegic, and so forth.According to WHO (2011), Approximately 10 percent or Approximately 23 million of the total population of Indonesia is a society that has limited capabilities and experience the phenomenon of the problem is almost the same with regard to the rights included in disabilities Among others: visual impairment, hearing impairment, mental retardation, physical disabilities, tuna barrel, learning Difficulties, behavioral disorders, gifted children, children with health problems. Another term for children with special needs is extraordinary children and children with disabilities. Due to the characteristics and constraints of being owned, disabled require any form of special education services that are tailored to the capabilities and potential, for example for the blind they require modification of the reading text into Braille and hearing impairments to communicate using sign language is Merdeka Square Malang has how many public activities that are around the square area as their shopping center.

\section{BASIC THEORY}

Public open space is an open space of the commons, where people perform functional activities and rituals in a community ties both everyday life and in the periodic celebration (Carr, 1992). The public spaces have a greater social role than just creating an interaction. At issue is the public space the citizens can be expressed, in which all persons are equal and there are no social differences. One of the main functions of public open space is as a vehicle for interaction between communities for a variety of purposes, both individuals and groups. In this case the public open space is part of the social system whose existence cannot be separated from social dynamics. The existence of public open space today has suffered setbacks primarily a function of the nature of openness. Some aspects that should be contained in a public open space often forgotten fact rarely ignored by planners and designers of the City. This coupled with the emergence of the development of public spaces such as building container as a container for social and economic activities which are essentially public space cannot be enjoyed by all levels of society. As a public space, universality is a major aspect that must be 
considered in the provision of a public open space. The existence of public open to consider various classes and status needs of the community that reflects the fulfillment of the needs of the whole society both class top to bottom, from normal society until people who have the physical ability is different from normal society, from children to adults and male or female (Purwanta, 2002).

System activity in a public space is closely related to the three main elements, namely hawkers as a support activity area, parking and pedestrian-related circulation pattern. Patterns of activity associated with the use of existing space, element fixed, semi-fixed elements and elements not fixed (Rapoport, 1982). The term people with disabilities are not only focused on those with disabilities but the term disabilities have the idea of a more flexible and comprehensive that people who have barriers temporarily or permanently in carrying out their daily activities, including pregnant women, children, the elderly, wheelchair users, crutches, blind, deaf, quadriplegic, and so forth. According to WHO data, approximately 10 percent or approximately 23 million of the total population of Indonesia is a society that has limited capabilities and experiences phenomenon similar problems with regard to the rights and obligations.

\subsection{Research Location}

\section{MATERIAL AND METHODS}

This research was conducted in Malang precisely at the activity room square Merdeka Malang as forming the environment and in particular on the adaptation of space activities for disabled people. The location was chosen because it is an icon of Malang is also a recreation place is never empty. The layout of the square is located because it is right in the heart of Malang and surrounded by leading shopping center and close to government agencies.

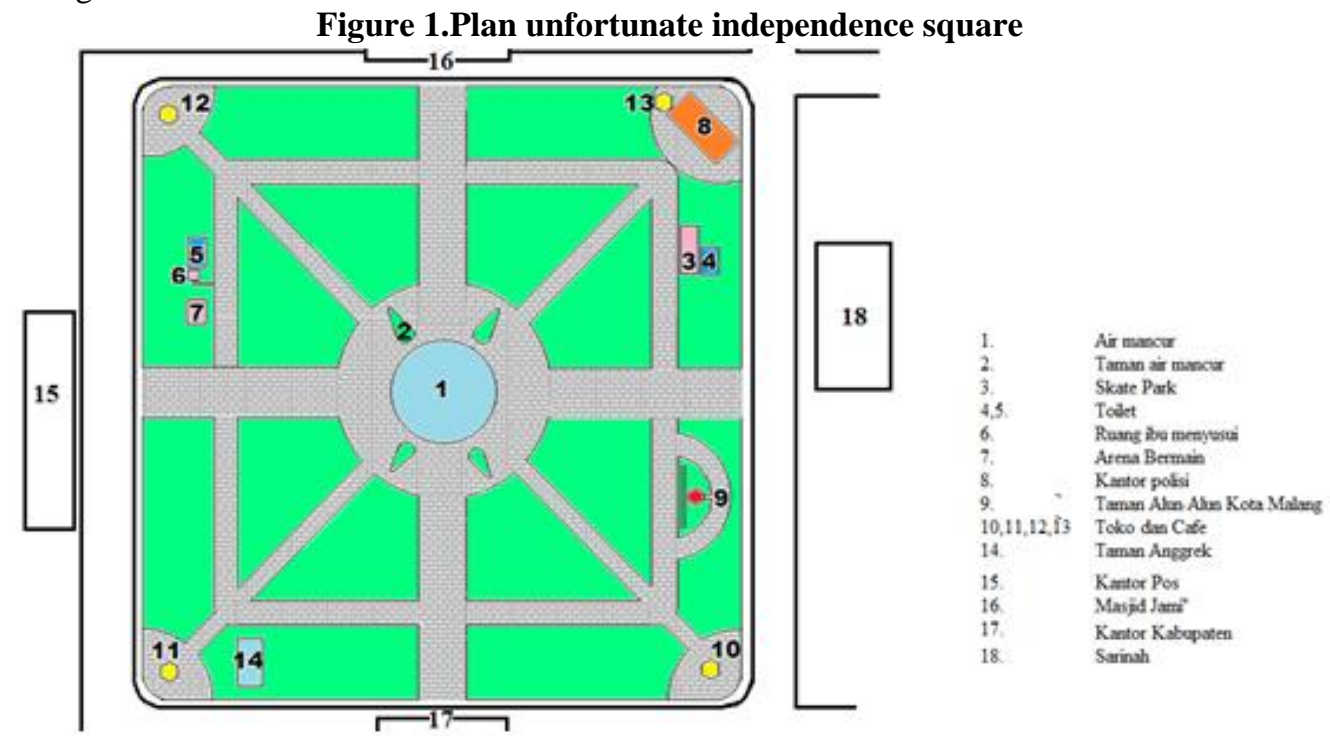

\subsection{Data Collection Methods}

The type of data collected in the form of primary data and secondary data. The collection of primary data collected through field surveys based on visual square Merdeka Malang, environmental and other architectural elements into details such as photos or record the current conditions. While secondary data are used to support the data in the study is the historical background of the square Merdeka Malang.

\subsection{Data Analysis}

This research is a descriptive study using a qualitative approach, where researchers aimed to describe and analyze the performance of adaptation to space activities for the disabled in the city open space as forming environment in the square Merdeka Malang. According to Patton (1990) using qualitative methods researchers can study specific issues more deeply and in detail. In accordance with the goals and objectives of the study, qualitative methods are used to obtain detailed information regarding the issues that are actually in the regulations on the provision of adaptation to space activities for disabled people, both in substance and completeness of its implementation. 


\section{RESULTS AND DISCUSSION}

Time is often used by people to visit and indulge in the square is at dusk. This is because many families who walk the child, at home office and return to the school hours. While at night is often used for people whose activities are concentrated in the fountain and dominated by teenagers. Accessibility (pedestrian) is an important factor for many users who indulge square and sit around enjoying the atmosphere of green in the city center.

\section{Figure 2. Seating}

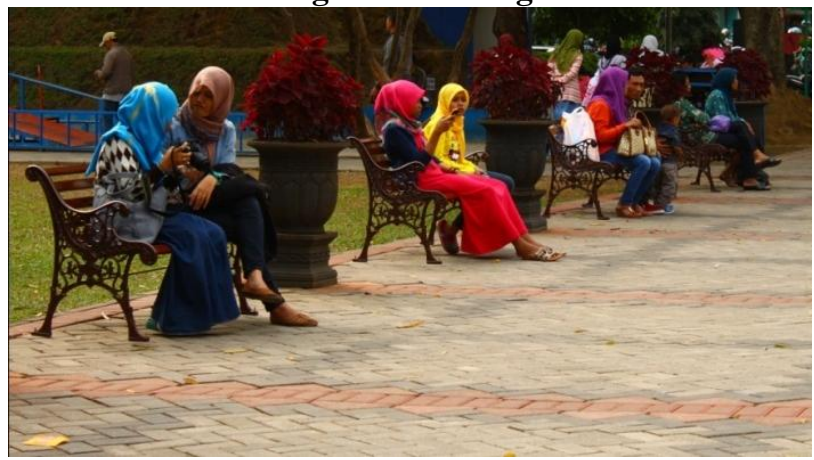

At the time of entry to the area of the square Merdeka Malang, it appears that the entrance area is very wide and makes it easier for the disabled to get in or out so as to provide easy access for wheelchair users. In addition, the square open space also provides a special place for mothers who breastfeed. In the pedestrian area created quite extensive and allows easy access for disabled people.
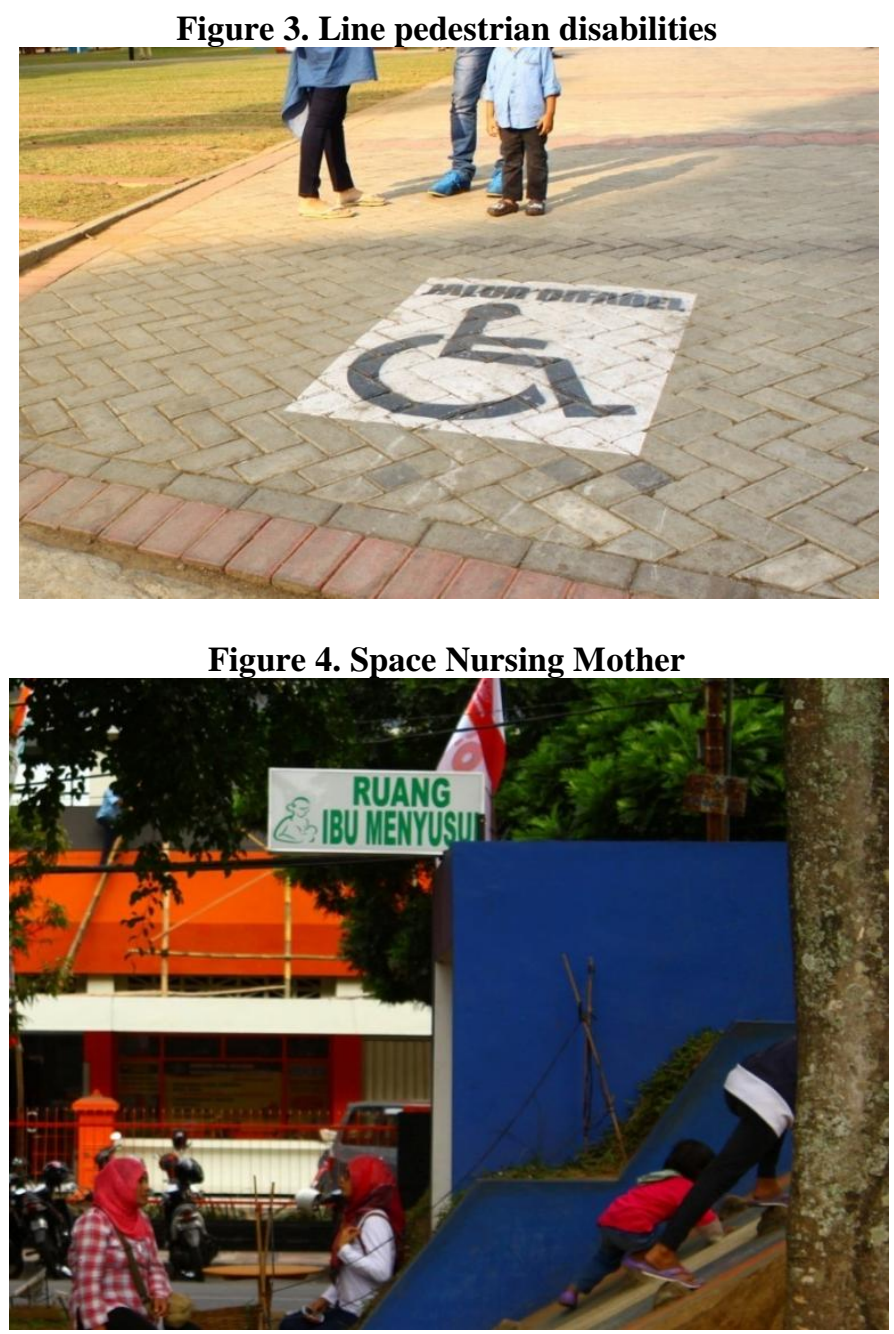
However, adaptation space activities disabled people in open spaces still experiencing difficulties in some aspects of the location. Some of the obstacles for the disabled in the open space are:

1. Parking the vehicle up and down. It is difficult for the disabled both visually impaired, wheelchair users, and users of semi ambulances to enter the area of the square of the vehicle parking area.

2. The washroom (toilet) do not have sanitation accommodate the needs of disabled.

3. signs or warnings have not been verbal, making it difficult for the disabled to be able to know the signs or warnings.

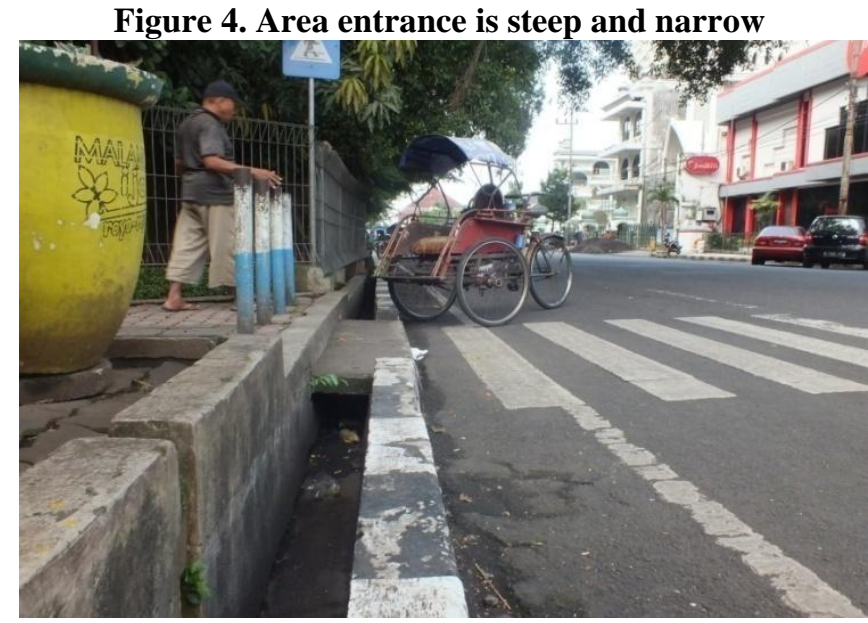

\section{CONCLUSION}

Based on the results and discussion shows that the positions and aspects of all-kan authentic adaptation of space activities for the disabled in the city open space with a square case study Merdeka Malang adaptation is not guaranteed supply of space activities for disabled people, especially in the city public open space. Although the government has issued several regulations on the disabled / handicapped, open spaces for disabled people still need to be improved. Friendly pedestrian path has been constructed with disabilities but there are a number of facilities and infrastructure that have not been fulfilled.

[1] Carr, Stephen. 1992. Public Space. USA: Cambride University Press.

[2] Patton, M. Q. 1990. Qualitative Evaluation and Research Methods. Newbury Park: Sage Publications.

[3] Purwanta, Setia Adi. 2002. Splitting Fear Being Strength, Stories Advocacy in Indonesia. Jogjakarta Insists Press.

[4] Rapoport, Amos. 1982. Human Aspect of Urban Form: toward a man environment approach to urban form and design. USA: Pergamon Press.

[5] WHO (2011). World Report on Disability. W. H. Organization. Malta, WHO Library 350. 